\title{
Predicting Impacts of Climate Change on Maize Productivity in Egypt
}

\author{
S. E. Sadek and M. F.A. Saba \\ Field Crops Research Institute, Agricultural Research Centre \\ (ARC), Giza, Egypt.
}

\begin{abstract}
7 HE POTENTIAL effects of climatic change impose great challenges on agriculture scientists to diminish expected detrimental consequences of global warming. Two available databases, with results and observations of the last ten full seasons from 1997 to 2006 of maize national campaign and meteorological records of the same period databases, were used to establish preliminary models illustrating climatic factors affecting maize grain yield. Five models were restricted for maize hybrids, i.e. SC.10, SC.155, TWC.324 and Nefertity hybrid in addition to a general model for maize hybrids deduced from an average performance of 20 maize hybrids either single or three way crosses. Data of grain maize yield production were collected by scientific teams who monitored demonstration fields distributed over 17 governorates during 10 years, where the recommended technological package was accurately executed.
\end{abstract}

The polynomial models that deduced depending on growing degree days (GDD) and their base temperatures as well as air relative humidity (ARH) illustrated at least $99 \%$ of the variance in the maize productivity over governorates and years. Forecasting the potential impact of climate changes on maize grain yield under some scenarios of global warming predicted slightly decrease due to temperature increase and low ARH percentage. Maize grain yield productivity will be slightly declined in some governorates as Aswan. By contrast, ARH increments give quite satisfactory relief effects from heat increasing.

Keyword: Maize, Climate change, Multiple regression, Predict .

A global assessment of the potential impact of climate change on world food supply suggests that doubling of the atmospheric carbon dioxide $\left(\mathrm{CO}_{2}\right)$ concentration will lead through multiple indirect interactions, to only a small decrease in global crops production. But developing countries are likely to bear the brunt of the problem, and simulations of the effect of adaptation measures by farmers imply that these will do little to reduce the disparity between developed and developing countries (Rosenzweig \& Parry, 1994).

A comprehensive review of climate change on food security was presented by El-Itriby (2009). The positive effects of atmospheric carbon dioxide concentrations on many crops were mentioned. In contrary, numerous adverse effects of temperature increments on agriculture systems were presented like reducing cereal crop production, increasing sea levels, occurrence of extreme 
events such as drought and floods, changing precipitation patterns, weakening pastures which will lead to reduced livestock productivity and increased livestock mortality and increasing the salinity of soils and groundwater. Climate change will cause new patterns of pests. Nevertheless, the expected decrease of maize grain yield was cited after by El-Shaer et al. (1997), who predicted $19 \%$ reduction by 2050 and were cited also by Hassanein \& Medany (2007) who foreseen the reduction as $14 \%$ and $20 \%$ by 2050 and 2100 , respectively. On the other hand, Kucharik \& Serbin (2008) stated that if modest increases in total summer precipitation (i.e. $50 \mathrm{~mm}$ ) occurred, maize grain yield may be boosted by $5-10 \%$, counteracting a portion of the negative effects associated with the increased temperature. While northern US Corn Belt regions such as Wisconsin may benefit from a warmer climate and lengthen the crop-growing period in spring and autumn, mid- to high-latitude crop productivity may be challenged by additional summertime warming unless adaptive measures are taken.

The current status of Egyptian agriculture was assessed by Rosenzweig \& Hillel (1994); they posed scenarios that will be faced under climatic change and their consequences on Egypt. The fact that Egyptian agriculture is entirely based on irrigation from the Nile was considered, so the water supplementations and consumption via evapotranspiration of green cover will be influenced by the imposed atmosphere. Therefore, the significant global warming expected from the enhanced greenhouse effect may have detrimental consequences on Egyptian agriculture. They expected that Egypt will experience a significant rise of mean temperature in the coming decades for doubled atmospheric $\mathrm{CO}_{2}$. They stated that Egypt appears to be particularly vulnerable to climate change, since the warmer climate will impose a greater evaporation demand. Sensitive crops are likely to suffer from increased water stress as well as yields may suffer from the hastened maturation in a warmer climate with greater infestations of pests (Rosenzweig \& Hillel, 1994). Eid (1994) used modeling simulations and predicted that maize and wheat yields would decline in the Delta by as much as 30 percent and in Middle Egypt by more than $50 \%$.

Given the rate of projected environmental change for the $21^{\text {st }}$ century, urgent adaptation and mitigation measures are required to slow down the on-going harmful effects on crop yields. In Croatia, Visnja Vucetic (2009) reported that further increase in minimum and maximum temperature and decrease in precipitation will shorten the maize vegetative period around a month, reducing the maize yield about $9 \%$. Croatian farmers shifted planting date (earlier sowing date) as one potential adaptation process in agriculture but did not significantly increase maize yield.

Yoichi Torigoe (1986) stated that the growth stage concept has been introduced to describe a generalized yield determining process of maize. The growth stages proposed were useful in describing a generalized yield determining process, but were inappropriate in the discussion of adaptability and productivity of maize.

Egypt. J. Agron. 33, No.1 (2011) 
The objectives of this research paper are to predict the climate change impact on maize grain yield in different Egyptian governorates through establishing simulation model depending on the two available databases (yield of demonstration fields for the last 10 years 1997-2006 of the maize national campaign and recorded climate data of the same period databases). Also, to investigate the probability of adaptation measures to mitigate climate change effects on maize.

\section{Material and Methods}

The maize national campaign which was proposed to increase maize productivity started in the period from 1980/1983 in some governorates and extended up to 2006 to cover all maize cultivated Egyptian regions including 22 governorates. Both scientific and extension teams cooperated to supervise and encourage farmers to implement all recommendations of agricultural practices using highly productive hybrids, proper sowing date, required soil preparation, suitable plant density, enough fertilizer inputs, suitable irrigation and required pest controls. Among campaign activities, several pairs of adjacent demonstration fields, one for the most 10 productive single maize hybrids and one for the most 10 productive three way maize hybrids were planted during the period from 15 to 28 of May each summer season at each governorate, where optimum inputs were applied to maximize productivity, but climatic factors were uncontrolled so that significant variations in grain yield resulted due to these factors. However, the number of these fields was proportional to the cultivated area in each governorate, while the time span of full seasons started from May 15 to September 15, yearly. The productivity of each hybrid for every demonstration field was accurately estimated and recorded. The data were recorded in Access Database. Unfortunately, this database contains only the average grain yield for each hybrid in every governorate from 1996 till 2006 and some of the demonstrated hybrids were replaced yearly by newer ones; but only four hybrids matched in the current investigation because they have complete records viz., SC 10, SC 155, TWC 324 and hybrid spelling in English Nefertity as well as the average of 20 crosses representing maize hybrid productivity.

The data of 17 governorates were employed in the course of this paper; these governorates were Kafrelshaikh, Behera, Dakahlia, Menofia, Gharbia, Sharkia, Giza, Fayom, Menia, Assuit, Sohag, Qena, Aswan, Beni-swif, Domiat, Ismailia and Al-Kalioubia. All of these governorates possess weather stations. Table 1 represents their average temperature during May, June, July, August and September of these governorate, as well as mean of grain yield in ardap $=155 \mathrm{~kg}$ per faddan for each governorate.

The collected data were recorded in Access Database beginning from 1997 growing season till the end of national maize campaign activities in summer season of 2006. Simultaneously, another database for weather data was established; daily maximum and minimum temperature and minimum and maximum relative humidity were only regarded to this preliminary study. 
Matched data from these two databases were extracted therefore; both weather and yield records were related to the same governorate and the same season; these data comprised 86 records.

TABLE 1. Average temperature and grain yield (ardab/feddan) during maize growing seasons in 17 governorates.

\begin{tabular}{|l|c|c|c|c|c|c|c|}
\hline Governorate & MAY & JUN. & JUL. & AUG. & SEP. & Mean & Rank \\
\hline Domiat & 21.8 & 23.9 & 26.5 & 26.4 & 25.5 & 24.8 & 1.0 \\
\hline Kafrelshakh & 23.1 & 24.9 & 28.1 & 26.3 & 25.0 & 25.5 & 2.0 \\
\hline Gharbia & 23.1 & 25.6 & 26.9 & 26.9 & 24.9 & 25.5 & 3.0 \\
\hline Giza & 23.5 & 26.8 & 27.2 & 27.3 & 25.5 & 26.1 & 4.0 \\
\hline Kaluobia & 23.2 & 26.2 & 27.4 & 27.5 & 26.4 & 26.1 & 5.0 \\
\hline Sharkia & 24.0 & 27.3 & 27.8 & 27.9 & 25.5 & 26.5 & 6.0 \\
\hline Menia & 25.1 & 25.6 & 27.7 & 28.4 & 25.9 & 26.5 & 7.0 \\
\hline Behera & 25.3 & 26.5 & 27.8 & 27.9 & 26.5 & 26.8 & 8.0 \\
\hline Menofia & 25.9 & 26.7 & 27.7 & 27.1 & 26.6 & 26.8 & 9.0 \\
\hline BeniSwif & 25.2 & 27.3 & 28.4 & 28.4 & 26.3 & 27.1 & 10.0 \\
\hline Ismailia & 24.7 & 27.2 & 28.9 & 29.2 & 26.7 & 27.3 & 11.0 \\
\hline Fayoum & 25.5 & 28.2 & 29.2 & 30.3 & 28.1 & 28.3 & 12.0 \\
\hline Sohag & 27.0 & 29.5 & 28.9 & 29.3 & 27.2 & 28.4 & 13.0 \\
\hline Assiut & 27.2 & 29.4 & 29.7 & 29.7 & 27.5 & 28.7 & 14.0 \\
\hline Dakhlia & 28.6 & 30.8 & 31.4 & 30.8 & 28.3 & 30.0 & 15.0 \\
\hline Qena & 30.3 & 31.1 & 32.2 & 31.9 & 30.6 & 31.2 & 16.0 \\
\hline Aswan & 31.9 & 33.5 & 33.9 & 34.2 & 32.0 & 33.1 & 17.0 \\
\hline
\end{tabular}

Several growth stages were proposed for maize growth depending on plant phenology, ontology and morphological features; herein three main stages are recognized, i.e., seedling and vegetative growth, flowering and fertilization stage and grain filling as well as full maturity stage. These stages differently require and respond to temperature and other metrological factors (Visnja Vucetic, 2009; Allison \& Daynard, 1979; Hunter, 1974; Cooper, 1979 and Yoichi Torigoe, 1986).

Therefore, the maize growing season (120 days) was assumed to be composed by 3 equal periods synchronized with the growth stages to study the environmental factors for each period individually. Five environmental factors for each period were assumed having potential to affect maize growth and consequently its productivity, i.e., growing degree days (GDD), quadratic temperature effect $\left(\mathrm{T}_{\mathrm{i}}^{2}\right)$ (a quadratic polynomial temperature function), maximum temperature during specific period $\mathrm{tx}_{\mathrm{i}}$, average relative humidity $(\mathrm{ARH})$, required humidity to complete saturation $\left(\mathrm{RHS}_{\mathrm{i}}\right)$ and the interaction between temperature and $\mathrm{RHS}_{\mathrm{i}}$ which was expressed as $\left(\mathrm{T}_{\mathrm{a}} \times \mathrm{RHS}_{\mathrm{i}}\right)$; so the effect of 15 independent factors were examined to find out their significant partial regression effect on grain yield, the dependent variable.

Egypt. J. Agron. 33, No.1 (2011) 
The GDD values were calculated according to Stewart et al.(1998):

$$
\mathrm{GDD}_{\mathrm{si}}=\sum_{j=1}^{40}\left(\mathrm{t}_{\mathrm{x}}+\mathrm{t}_{\mathrm{m}}\right) / 2-10
$$

where $\mathrm{GDD}_{\mathrm{si}}$ is the total GDD of stage $\mathrm{i}\left(\mathrm{i}=1\right.$ to 3 ) in ${ }^{\circ} \mathrm{C}, \mathrm{t}_{\mathrm{x}}$ is the maximum daily temperature, $t_{m}$ is the minimum daily temperature and the constant 10 is the base temperature or the lower threshold under which the growth rate of maize is zero (Stewart et al., 1998). Figures 1 and 2 illustrate the variation of GDD and ARH in the 17 governorates of the three growth stages.

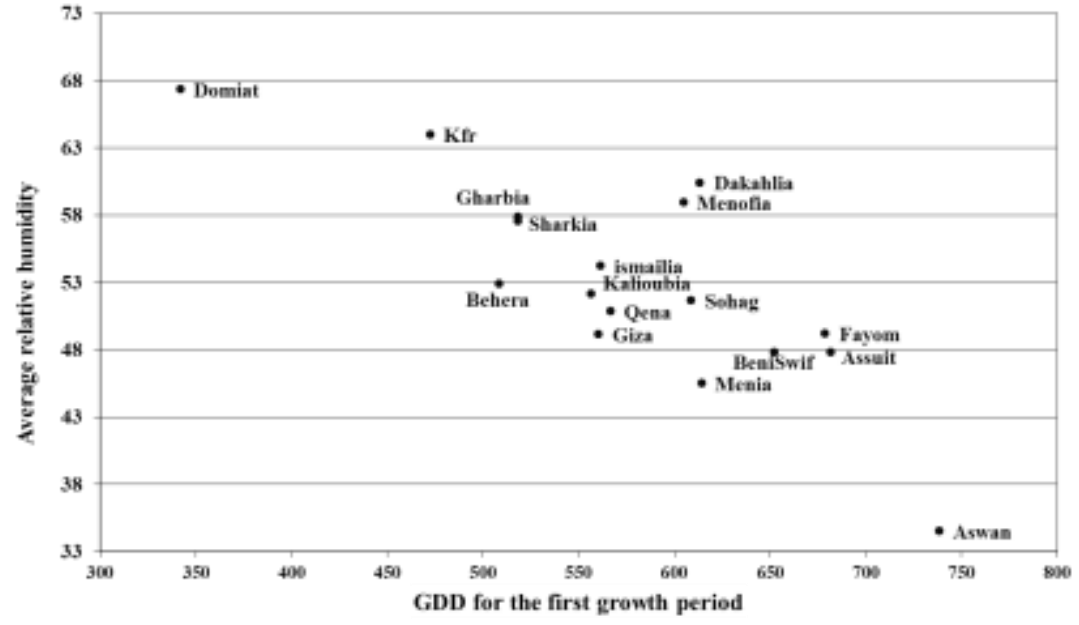

Fig. 1. Average GDD and ARH for first growth stage (S1) of maize growing season in Egyptian governorates .

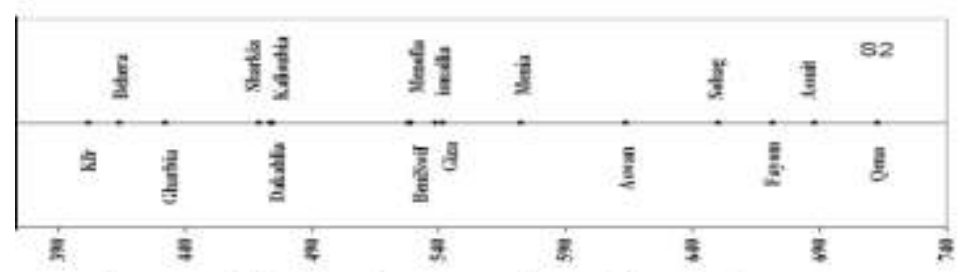

Average GDD fore the second growth period

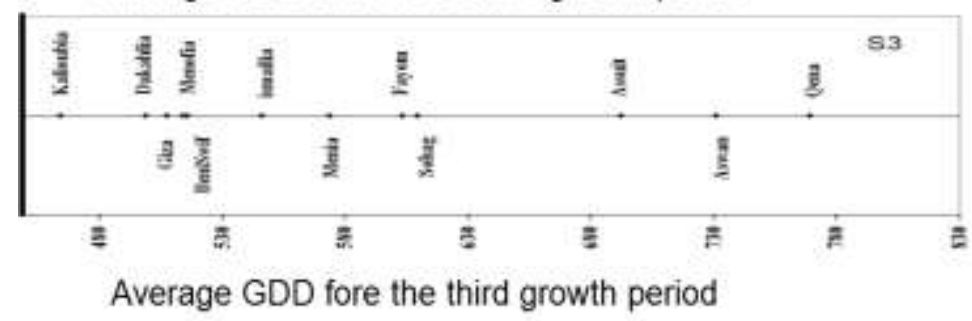

Fig. 2. Average GDD and ARH for S2 and S3 growth stages of maize growing season in Egyptian governorates. 
Statistical analysis

In order to study the relationship between maize yield and climate factors across Egypt regions, multiple regression models were developed using the five environmental factors for the three assumed growth stages as the independent variable and maize grain yield, the dependent variable, of the four mentioned hybrids as well as the average yield of 20 maize hybrid as a representatives of Egyptian maize hybrids. The analyses were performed separately for every hybrid, so predictor variables could potentially be different for any specific hybrid.

To do so, the regressions between all of the possible 15 climate variables and grain yield using the available 86 records were performed. Must enunciate here the polynomial for testing the multiple regression were detected after excluding the less significant variables while running multiple regressions using GenStat Sixth Edition several times. Since, the grain yield at GDD $=0$ must be also zero, the intercept was restricted to zero.

\section{Results and Discussions}

Table 2 shows the estimated partial regression coefficients of 7 effective climate factors affecting grain yield of some maize hybrids. The $\mathrm{R}^{2}$ of these models were about $99 \%$, ensuring the role of climatic factors when the recommended agricultural practices and inputs were optimized to maximize grain yield. The GDD during of the first 40 days of maize season linearly increases the resulted yield. The increment magnitude slightly differed between the studied hybrids except for SC10 that displayed higher partial regression coefficient. The second stage (40 days) of maize growth season displayed two significant components in the regression for accumulated heat units, i.e., linear and quadratic items. However, in this period the most sensitive processes occurs, i.e., conversion from vegetative to reproductive stages, tassel appearance, silking and fertilization.

TABLE 2. Partial regression coefficients of climate factors affecting grain yield of four maize hybrids and average grain yield for Egyptian maize hybrids.

\begin{tabular}{|c|c|c|c|c|c|c|c|c|}
\hline Hybrid & GDD $_{\text {s1 }}$ & GDD $_{\text {s2 }}$ & GDD $_{\mathrm{s} 3}$ & $\mathrm{RHS}_{\mathrm{s} 1}$ & $\mathbf{T}_{\mathrm{s} 1 \times \mathrm{RHSs} 1}$ & $\mathbf{T}_{\mathrm{s} 2}^{2}$ & $\mathbf{T}_{\mathrm{s} 3}^{2}$ & $\mathbf{R}^{2}$ \\
\hline $\begin{array}{l}\text { Maize } \\
\text { hybrids }\end{array}$ & & $\mathrm{P}<0.01$ & & & & & $\begin{array}{l}-0.0948 \\
P=0.10\end{array}$ & 0.99 \\
\hline Neffertity & $\begin{array}{l}0.0901 \\
\mathrm{P}<0.01\end{array}$ & & & $\begin{array}{l}1.6602 \\
\mathrm{P}<0.01\end{array}$ & & $\begin{array}{l}0.2584 \\
\mathrm{P}<0.01\end{array}$ & $\begin{array}{l}-0.0486 \\
\mathrm{P}=0.48\end{array}$ & 0.99 \\
\hline TWC 324 & $\begin{array}{l}0.0989 \\
\mathrm{P}<0.01\end{array}$ & $\begin{array}{l}-0.3475 \\
\mathrm{P}<0.01\end{array}$ & $\begin{array}{l}0.1182 \\
\mathrm{P}=0.08\end{array}$ & $\begin{array}{l}1.7252 \\
\mathrm{P}<0.01\end{array}$ & $\begin{array}{l}-0.0740 \\
\mathrm{P}<0.01\end{array}$ & $\begin{array}{l}0.2765 \\
\mathrm{P}<0.01\end{array}$ & $\begin{array}{l}-0.0916 \\
\mathrm{P}=0.12\end{array}$ & 0.99 \\
\hline SC 155 & $\begin{array}{l}0.0974 \\
\mathrm{P}<0.01 \\
\end{array}$ & $\begin{array}{l}-0.4341 \\
\mathrm{P}<0.01\end{array}$ & $\begin{array}{l}0.1730 \\
\mathrm{P}=0.02\end{array}$ & $\begin{array}{l}1.7037 \\
\mathrm{P}<0.01\end{array}$ & $\begin{array}{l}-0.0725 \\
\mathrm{P}<0.01\end{array}$ & $\begin{array}{l}0.3680 \\
\mathrm{P}<0.01\end{array}$ & $\begin{array}{l}-0.1514 \\
\mathrm{P}=0.02\end{array}$ & 0.99 \\
\hline SC 10 & $\begin{array}{l}0.1171 \\
\mathrm{P}<0.01\end{array}$ & $\begin{array}{l}-0.4209 \\
\mathrm{P}<0.01\end{array}$ & $\begin{array}{l}0.0997 \\
P=0.27\end{array}$ & $\begin{array}{l}2.0806 \\
\mathrm{P}<0.01\end{array}$ & $\begin{array}{l}-0.0881 \\
\mathrm{P}<0.01\end{array}$ & $\begin{array}{l}0.3421 \\
\mathrm{P}<0.01\end{array}$ & $\begin{array}{l}-0.0801 \\
\mathrm{P}=0.31\end{array}$ & 0.99 \\
\hline
\end{tabular}

$\mathrm{GDD}_{\mathrm{s} 1}, \mathrm{GDD}_{\mathrm{s} 2}$ and $\mathrm{GDD}_{\mathrm{s} 3}$ are the growing degree days of the successive growth stages; $\mathrm{RHS}_{\mathrm{s} 1}$ is the required humidity for saturation of the first growth stage and $\mathrm{T} 2_{\mathrm{s} 2}, \mathrm{~T} 2_{\mathrm{s} 3}$ are the quadratic polynomial temperature function of second and third growth stages.

Egypt. J. Agron. 33, No.1 (2011) 
In contrary, the last forty days period of maize season had given different trend of response to accumulated heat units. The single cross 155 hybrid displayed highly significant coefficients for either linear or quadratic terms but the three way cross 324 displayed terms with probability ranged between 0.08 and 0.12 , while neither linear or quadratic terms reached significance for single cross 10 or Neffertity hybrids. The potential explanations for this behavior are insensitivity of grain filling process to warmer weather or to the Egyptian hybrid durability which is less than 120 days.

Both RHS percentage and its interaction with temperature during the first forty days of maize growth displayed highly significant partial regression coefficients, but their effects were conflicted. Increasing air requirement to more RHS had positive effects that may attribute to the increase of evapo-transpiration and nutrients translocation. The interaction of RHS with temperature $\left(T_{\mathrm{s} 1} \mathrm{x}\right.$ $\mathrm{RHS}_{\mathrm{s} 1}$ ) displayed negative effects, which encourage us to find out the point of equalizing both RHS and $T_{s 1} R_{x} S_{s 1}$ effects. This point $\left(\mathrm{RHS}_{\mathrm{s} 1} \times 17701-\mathrm{T}_{\mathrm{s} 1} \mathrm{x}\right.$ $\mathrm{RHS}_{\mathrm{s} 1} \times 0.0749=0$ ) realizes at temperature results from divides the partial regression of RHS by the partial regression of Ts1 $\mathrm{x} \mathrm{RHS}_{\mathrm{s} 1}$ that ranges around $23.6{ }^{\circ} \mathrm{C}(1.7707 / .0749)$. However each centigrade degree of temperature increase displayed negative effect on maize grain yield and each decrease was accompanied by a positive effect. Another feature can be distinguished, above this point, increasing air RHS decreases deleterious effect of heat; and less than this point, air RHS increasing decreases the positive effect of heat.

\section{Model validation}

Data of the seventeen governorates for climate and yield of the studied hybrids which had been collected during 2005 season were used to validate the specific models. The simple correlation coefficients between the expected and observed yield were: 0.518 ( $\mathrm{P}=0.033), 0.423(\mathrm{P}=0.090), 0.500(\mathrm{P}=0.041), 0.627$ $(\mathrm{P}=0.006)$ and $0.410(\mathrm{P}=0.102)$ for maize hybrid, Neffertity, TWC 324, SC 155 and SC 10, respectively. These results reflect the effect of the significant levels of temperature terms associated with the three periods of fourty days. Nevertheless, the validation tests for these models encouraged the investigators to utilize them to forecast the impact of climate change.

\section{Forecasting effects of temperature and ARH changes}

Rosenzweig \& Parry (1994) represented 3 scenarios for doubled $\mathrm{CO}_{2}$ levels, discussed the other greenhouse gases effects and showed that the simulated climate would warm to the effective doubled $\mathrm{CO}_{2}$ level of approximately $4{ }^{\circ} \mathrm{C}$ by AD 2060. Therefore, the increment of $4{ }^{\circ} \mathrm{C}$ was respected in the course of this paper. Since this increment would be gradually taken place during the period longed until AD2060, the models were applied using additional 1, 2, 3 and $4{ }^{\circ} \mathrm{C}$ over the recorded data. ARH and its interaction with temperature displayed highly significant terms on grain yield, so different scenarios of changing ARH were also applied. 
The previous increments were added to the average temperature or ARH of each governorate. Figure 1 shows average GDD and ARH which were used for prediction. GDD and ARH for the first 40 days period (S1) ranged between two extremer governorates, i.e., Domiat, 342.1 and $67.4 \%$ and Aswan, 738.5 and $34.5 \%$ with averages at 576.4 and $53.1 \%$, respectively. For S2 and S3 the GDD ranged from 304.5 and 400 for Domiat to 712.9 and 769 for Qena Governorate with average of 530 and 534, respectively. These results apparently displayed the great variation existing among governorates and their consequences on grain yield.

The relative changes in grain yield, either increase or decrease estimation, were proportional to the average grain yield for each governorate and were presented in layout (Table 3). The governorates were ascended according their $\mathrm{GDD}_{\mathrm{S} 1}$ that grouped governorates had similar response to climate changes. The average response of grain yield in entire Egypt indicated that warmer climate was favorable for maize, since there were yield increases of $0.28,1.9,4.8$ and $9.11 \%$ for temperature increasing $1,2,3$ and $4{ }^{\circ} \mathrm{C}$, respectively. This trend was amplified if the air ARH was increased and reversed if air ARH was decreased. These results conflicted with that reported by El-Shaer et al. (1997) and Hassanein \& Medany (2007) who forecasted negative effects, but they didn't pointed to air ARH. Although the forecasting threaten is conditioned by the air ARH decline more than $4 \%$, which didn't surpass $5 \%$ of maize production, it might be doubted and uncertain because this prediction was estimated for all maize hybrid over Egyptian areas. It is believed that this prediction would diverge if it depends on governorate-specific hybrid with actual sowing areas.

Regarding the impact of climate change on different Egyptian regions and their governorates, we could categorize them in three groups. The first group contains governorates close to the Mediterranean Sea where lowest GDD for entire maize growth season accompany with high air ARH percentage. The predicted responses to the temperature increase are mostly negative but the decrease rate reversely associated ARH. The highest decrements due to temperature occur at highest ARH. This group consists of Domiat, Kafrelshaikh, El-Behera and El-Gharbia.

The second group consists of Aswan governorates where every one ${ }^{\circ} \mathrm{C}$ increase accompanies with its current ARH raise the negative effects of climate changes on maize grain yield; this negative effects would be intensified by ARH decrease, in contrast, increasing ARH than its average would result positive effects temperature increasing.

The third group represents the main Egyptian area of maize; it contain all other governorates that mostly respond positively for warm weather and temperature increase inside the expected range, i.e., $4{ }^{\circ} \mathrm{C}$ until 2050.

In this paper the prediction mainly depended on GDD and ARH percentage. The benefit effects of $\mathrm{CO}_{2}$ increasing was neglected, Rosenzweig \& Parry (1994) reported that the increased rates of net photosynthesis and reduced stomatal opening as direct physiological effects of $\mathrm{CO}_{2}$ increase.

Egypt. J. Agron. 33, No.1 (2011) 
PREDICTING IMPACTS OF CLIMATE CHANGE ON MAIZE .... 
Finally, it must be noted the important role of air ARH percentage as adaptation process to alleviate climate change effects on maize. Cavero et al. (2009) studied sprinkler irrigation and its consequences on microclimatic changes surrounding maize plant. They found that sprinkler irrigation strongly modified maize canopy temperature by 4 to $6^{\circ} \mathrm{C}$, transpiration, leaf water potential (LWP) and decreased air temperature for a short period after the irrigation event. They added that the decrease in maize canopy temperature could be positive or negative, but the increase in LWP is a positive effect. Therefore modifying irrigation systems in Egypt may alleviate detrimental climate change effects on maize.

\section{Conclusion}

The foreseen changes in grain yield of maize presented on Table 2 aren't too obscure, since the expected $\mathrm{CO}^{2}$ will be doubled and the consequence temperature increasing limited to $4^{\circ} \mathrm{C}$; in addition this increment wouldn't surpass the highest temperature border except in Qena and Aswan governorates (see Fig. 1,2). Moreover, the areas covered by maize are larger in northern than the southern governorates where temperature increments more effective.

The current investigation revealed the important role of ARH and its interactions with temperature fluctuation on maize yield. Therefore, the predicted impacts of climate change on maize productivity have to depend on most climatic factors, specially temperature and relative humidity. The expected increment of temperature $\left(4^{\circ} \mathrm{C}\right)$ until 2050 may cause limited effects when ARH still as it is or ARH increasing but the effect may be amplified under lower ARH. Opportunely, the ARH can be controlled even on microclimatic changes surrounding plants through different irrigation methods. It is recommended more investigations on ARH effects and studying the distribution of cultivated areas and associated temperature and ARH.

\section{References}

Allison, J.C.S. and Daynard, T.B. (1979) Effects of change in time of flowering, induced by altering photoperiod or temperature, on attributes related to yield in maize. Crop Sci. 19, 1-4.

Cavero, J., Medina, E.T., Puig, M. and Martínez-Cob, A. (2009) Sprinkler irrigation changes maize canopy microclimate and crop water status, transpiration, and temperature. Agr. J. 101 (4), 854-864.

Cooper, P.J.M. (1979) The association between altitude, environmental variable, maize growth and yield in Kenya. J. Agric. Sci. (Cambridge), 93, 635-649.

Eid, H.M. (1994) Impact of climatic changes on simulated wheat and maize yields in Egypt. In: RosenWeig and A. Iglesias (Ed.) "Implications of Climate Change for International Agricultre: Crop Modeling Study". U.S. Environmental Protection Agency. Washington, DC.

Egypt. J. Agron. 33, No.1 (2011) 
EL-Itriby, Hanaiya (2009) Climate change and food security. http://www. ncwegypt. com/Euromed/docs/Climate_Change_and_Food_Security New.(2009) ppt\#269,1.

El-Shaer, H.M., Rosenzweig, C., Iglesias, A., Eid, M.H. and Hillel, D. (1997) Impact of climate change on possible scenarios for Egyptian agriculture in the future. "Mitigation and Adaptation Strategies for Global Change", Vol. 1, pp. 233-250. [ABSTRACT].

GenStat Release 6.2 (PC/Windows XP) Lawes Agricultural Trust (Rothamsted Experimental Station)

Hassanein, M.K. and Medany, M.A. (2007) The impact of climate change on production of maize (Zea mays L.). International Conference on Climatic Changes and their Impacts on Coastal Zones and River Deltas: Vulnerability, Mitigation and Adaptation, April 23-25, 2007, Alexandria, Egypt, pp. 271 -288.

Hunter, R.B., Hunt, L.A. and Kannenberg, L.W. (1974) Photoperiod and temperature effects on corn. Can. J. Plant Sci. 54, 71-78

Kucharik, Christopher J. and Serbin, Shawn P. (2008) Impacts of recent climate change on Wisconsin corn and soybean yield trends. Environ. Res. Lett. 3, 034003 (10pp).

Rosenzweig Cynthia and Hillel, Daniel (1994) Egyptian agriculture in the $21^{\text {st }}$ century. International Institute for Applied Systems (IIASA), CP-94-12.

Rosenzweig Cynthia and Parry, M. L. (1994) Potential impact of climate change on world food supply. Nature. VOL 367- 13 Jan 1994.

Stewart, D.W., Dwyer, L.M. and Carrigan, L.L. (1998) Phenological temperature response of maize. Agron. J. 90, 73-79.

Visnja Vucetic (2009) Modelling of maize production and adaptation to climate change in Croatia. Available online at Vucetic@ cirus.dhz.hr and meteorological and hydrological service, http//meteo.hr

Yoichi Torigoe (1986) A conceptual model of developmental phases of maize on the basis of the relationship between differentiation and growth of vegetative and reproductive organs. Japan J. Crop Sci. 55(4), 465-473.

(Received 7 / 6/2011, accepted 22/11/2011) 


\title{
تأثير التغيرات المناخية المتوقعة علي إنتاجية محصول حبوب الذرة الثامية في مصر الثفر
}

\author{
صنادق الثحات صادق و ميشيل فخري أبادير سابا

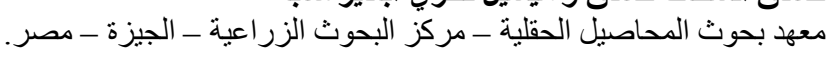

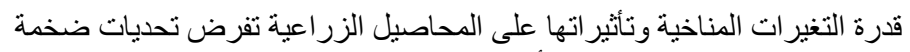

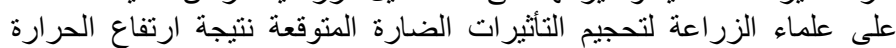

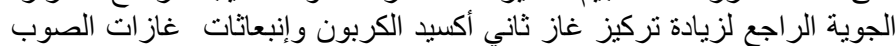

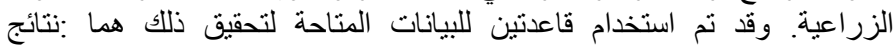

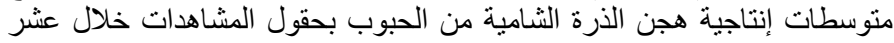

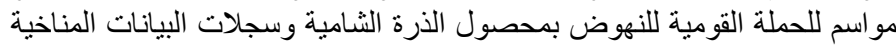

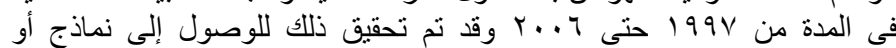

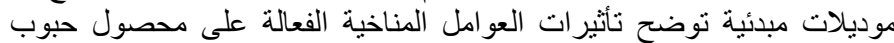

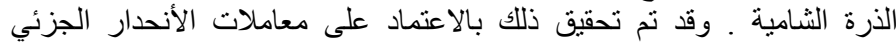

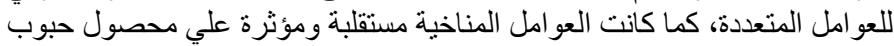

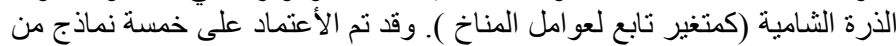

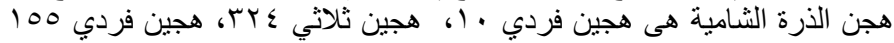

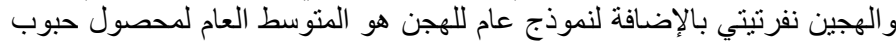

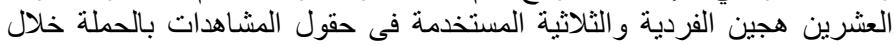

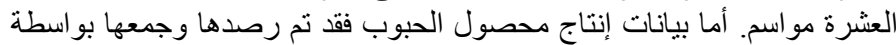

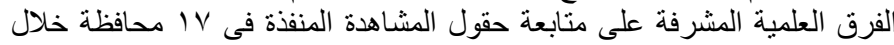

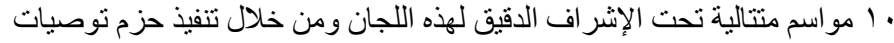
الفنية لتعظيم الإنتاج بكل دقة.

النماذج متعددة الفقرات (Polynomial models) م والمتوصل إليها

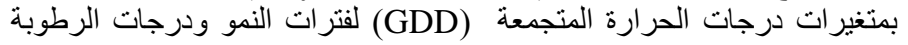
النسبية للجو كانت كافيه لشرح 99\% \% من تباينات منوسطات إنتاجية محصول الحبوب في السنوات و المحافظات المختلفة (

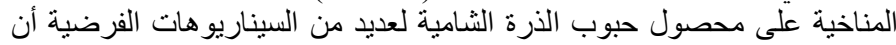

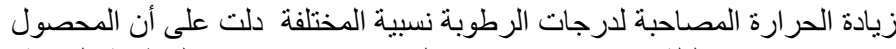

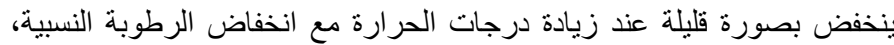

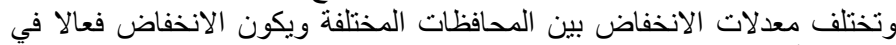

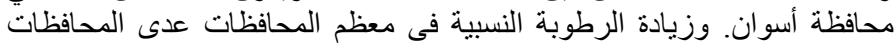

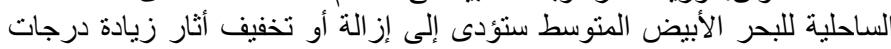

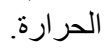

